\title{
Ventricular Tachycardia/Ventricular Fibrillation Arrest
}

National Cancer Institute

\section{Source}

National Cancer Institute. Ventricular Tachycardia/Ventricular Fibrillation Arrest. NCI

Thesaurus. Code C99522.

A cardiac arrest attributed to ventricular tachycardia or ventricular fibrillation. 